University of Warwick institutional repository

This paper is made available online in accordance with

publisher policies. Please scroll down to view the document

itself. Please refer to the repository record for this item and our

policy information available from the repository home page for further information.

To see the final version of this paper please visit the publisher's website. Access to the published version may require a subscription.

Authors: Mick Carpenter

Title: $\quad$ A Third Wave, Not a Third Way? New Labour, Human Rights and Mental Health in Historical Context

Year of 2009

publication:

Link to http://dx.doi.org/10.1017/S1474746408004740

published

version:

Publisher None

statement: 



\section{A Third Wave, Not a Third Way? New Labour, Human Rights and Mental Health in Historical Context}

\section{Mick Carpenter}

Department of Sociology, University of Warwick

E-mail:m.j.carpenter@warwick.ac.uk

This historically situated, UK-based review of New Labour's human rights and mental health policy following the 1998 Human Rights Act (HRA) and 2007 Mental Health Act (MHA), draws on Klug's identification of three waves of human rights. These occurred around the American and French Revolutions, after World War II, and following the collapse of state communism in 1989, and the article assesses impacts on mental health policy up to and including the New Labour era. It critiques current equality and rights frameworks in mental health and indicates how they might be brought into closer alignment with third wave principles.

\section{Introduction: the wider context of human rights and mental health}

This article discusses the impact of human rights law and discourse on mental health policy and practice in Britain. After first setting the historical context, I focus on the New Labour era and seek to assess the extent to which the new human rights and equalities framework enacted since 1997, alongside other health and social policy measures, has the potential to shift mental health policy along new and promising pathways or serves to reinforce well-trodden coercive tracks. In this context, I assess on the one hand whether the 1998 Human Rights Act (HRA) and the raft of anti-discrimination laws enacted in gender, race, disability, sexuality orientation, age, and religion and belief creates new possibilities for progressive mental health policy, which since 2007 have been brought together to be overseen by the Equalities and Human Rights Commission (EHRC). On the other hand, I assess the restrictions on rights involved in the 2007 Mental Health Act (2007). I also contextualise the discussion within broader features of the New Labour project and the tensions between discourses of rights and 'responsibilisation' and their implications for mental health policy.

The relative influence of external or internal forces in shaping mental health policy has been long debated, and I seek to move beyond this dichotomy. Drawing on pathdependency theory (Pierson, 2001) and critical realism (Bhaskar, 1975), I argue that mental health policy is a semi-permeable rather than either a hermetically sealed or determined field. Pathway analysis suggests that, once established, institutions are hard to change and tend to reproduce themselves. Change often happens within pathways, though sometimes it can set institutions along new trajectories. Critical realism can help to identify the contextual forces or 'generative mechanisms' that shape initial pathway formation, and which may also at a critical 'conjuncture' (Wilsford, 1995) overcome tendencies to reproduction in order to foster transformative change. I analyse these through Klug (2000) who argues that general advances in human rights have not been incremental but subject 
to three successive waves associated with pivotal moments in human history, which also transform their substantive focus. These occurred at the time of the French and American Revolutions at the end of the eighteenth century, after the end of the Second World War with the defeat of fascism and rise of the Cold War, and the end of Communism in 1989 and accelerating globalisation in the 1990s. These three waves give rise to three models or paradigms of human rights which for shorthand purposes I call liberal, egalitarian and participative, which seems to capture their key dimensions. I thus explore the extent to which these waves have shaped pathways taken within the mental health policy field. While I acknowledge that incremental changes occur at other times, I suggest that these key moments present opportunities to consolidate and extend them, but they do not in themselves externally 'determine' policies.

My key arguments are first that initially the impact of the first wave of human rights at the end of the eighteenth century was promising for mental health policy in raising the possibilities for a new approach to humane and effective treatment, but such impulses were substantially eroded by state custodialism and medical paternalism as the nineteenth century proceeded. Ironically, shifts to a more interventionist curative model in the first half of the twentieth century posed new human rights problems for mental health service users. My second argument is that a new climate of rights did emerge after World War 2 in Britain and other countries with implications for mental health policy, though they took time to come through. In addition, denial of civil and political (CP) rights in mental health was explicitly sanctioned by the European Convention on Human Rights (ECHR). In theory the policy shift to 'community care' opened up an agenda of improved liberties and enhanced social rights, but this was restricted by the medical paternalism of the 1959 Mental Health Act (MHA), fostering an individual pathology model which sanctioned low investment in non-medical social provision. It also failed to fully challenge stigma and discrimination in services and the wider society. Despite undoubted improvements, the social democratic welfare state thus reproduced the Cinderella status and controlling features of the previous system. Only when social movements challenged 'psychiatric oppression' from the late 1960s, and its role also in reproducing wider inequalities, such as those of class, race, gender and sexuality, was there some movement in the mental health system. This was weakly reflected in ECHR case law which led to the 1983 Mental Health Act (MHA). This granted some 'second wave' CP 'due process' rights to mental health users, hence change within the established paternalistic pathway, shoring up its essential features at a time of challenge. My third argument is that the mid-1980s closure of the mental hospitals by Thatcher was a key pathway change, opening up the possibility for a more responsive 'third wave' post asylum system with enhanced social and participative rights. While this possibility was initially signalled by the $1990 \mathrm{NHS}$ and Community Care Act, there was quickly an assertion of controlling imperatives in the wake of high profile 'carnage in the community' cases of killings by mental health users such Christopher Clunis (1996) and Michael Stone (1996).

My fourth argument is that New Labour measures have had a contradictory impact. Though elements of a third wave emphasis on social and participative rights can be detected, this is countered by a coercive communitarian approach that has produced the 2007 MHA. Since the 1998 Human Rights Act (HRA) is restricted largely to CP rights, the denial of which is actually sanctioned by the ECHR, it does not offer enormous scope for improving mental health. The article concludes, therefore, by identifying some of the influences that could place the mental health system more firmly on a third wave 
pathway. This pathway would overcome some of the ways in which mental health rights have been broached by first and second wave paradigms. Its emphasis on participation thus provides the potential to overcome controlling 'public interest' and medical paternalistic 'best interest' considerations. I define human rights broadly as a set of moral and political discourses about 'entitlements' rather than just a specific set of legally enforceable ('justiciable') principles. Thus, while encompassing socio-legal matters, they necessarily connect also to wider service and policy developments. The government itself has stated that its aim is to move beyond a narrowly legalistic approach to the 1998 HRA, encouraging public agencies to embed human rights as a 'culture', proactively shaping the way that services are designed and provided, rather than reactively responding to individual adverse legal judgements.

Mental health is relevant to human rights across a broad spectrum of issues. First mental health problems are common with perhaps around 25 per cent of people experiencing significant mental distress in any one year, and larger numbers likely to experience it at some time in their lives (Mental Health Foundation, 2007). Second, there is also clear evidence that unjust and preventable social inequalities of gender, class, ethnicity, sexual orientation, political status and other identities contribute to an increased risk of distress (e.g. Murali and Oyebode, 2004). Thirdly, people with mental health problems often become economically and socially vulnerable because their condition leads to diminished ability to exercise personal agency, and sometimes because their autonomy is removed by mental health professionals, both of which risk compromising their human rights. Further, people with mental health problems often experience discrimination in the wider society (Thornicroft, 2006). These problems are compounded by a mental health system that though now formally part of the health service welfare state, has deep roots in a deterrent poor law and close linkages with a punitive criminal justice system. For all these reasons mental health issues present many challenges for human rights, and arguably are a key general acid test of how seriously a society values them.

In what follows, I discuss how three waves of human rights have impacted on mental health policy, culminating in a critique of New Labour's record and a broad indication of how genuinely third wave policies might progress beyond it.

\section{The three waves of mental health policy and their effects}

The first wave and its aftermath in mental health policy (late eighteenth century to 1930s)

While features of human rights principles such as free expression, personal liberty and protection from arbitrary power can be traced back to ancient times (Ishay, 2004), it was only with the late eighteenth Century French and American Revolutions that efforts were made to constitutionally entrench them within a rationally designed and democratic system of government. This was one of the chief expressions of the Enlightenment era, which was primarily concerned with advancing 'negative' freedoms of personal liberty (Klug, 2000). The dominant feature was the rise of middle-class economic and political power under industrial capitalism, with prime emphasis on individual liberties and property rights, excluding 'positive' social rights that might require interference in them. Paradoxically, negative liberty was also associated with increased social discipline 
and obligations to 'self control', leading to systems of surveillance and 'technologies of the self' through reformed prisons, schools, workhouses, hospitals and asylums (Foucault, 1977; Scull, 1993). There was thus a fundamental tension between liberal and controlling impulses in Enlightenment thought, which by the end of the nineteenth century was resolved in favour of the latter in mental health policy. There were different national pathways. In France the image (not necessarily the reality) of Dr Phillipe Pinel in charge of the Bicêtre state institution in Paris unchaining the 'lunatics' at the height of the revolution in 1793 pictured lunacy reform as the medical equivalent of storming the Bastille (Weiner, 1994). In Britain, where the middle class transformed the old society from below, Tuke, a dissenting middle-class Quaker founded the lay Retreat for community members in York 1792. Along with the abolition of 'mechanical restraint' at the Hanwell public asylum in 1839 by Dr John Connolly, this paved the way for the 'enlightened' approach of the 1845 Lunacy Act, involving medical dominance over a state asylum system with an emphasis on 'moral' (psychological) and environmental causes and treatments. Reform was at least in part genuinely motivated by humanitarianism. Hunt (2007) argues that human rights discourses arose from eighteenth century campaigns against torture, slavery and cruel punishment. Jones's Fabian reformist account (1972: Chapter 4) shows how campaigners drew attention to unnecessary confinement and cruel treatment in order to discredit the old system and press for a state system.

Nevertheless, there were dissident libertarian voices, most notably John Perceval, who in founding the Alleged Lunatics' Friend Society in 1845 invoked English civil liberties traditions. Perceval dismissed moral treatment, the dominant treatment principle of the 1845 Act, as 'repression by mildness and coaxing, and by solitary confinement' (Hervey, 1986: 253). This initiated civil liberties campaigns against 'wrongful confinement', which through the 1890 Lunacy Act instigated greater legal oversight of admissions to middleclass users of private asylums. While Jones (1972) decried the 'triumph of legalism' for heightening custodialism for those 'rightly' confined, custodialism was in fact well established in the public asylum system, sanctioned by eugenicist concerns to exclude the 'unfit' from society (Scull, 1993). Thus, an institution originally inspired by human rights principles ended up breaching them, first by forcibly removing people who were different and/or disabled, and then subjecting them to regimented and often abusive treatment. The history of compulsory treatment, as documented by Fennell (1996), thus challenges the idea that medical discretion has protected mental health service users' 'best interests'. First, the development of sedatives and other forms of 'chemical constraint' helped to keep the inmate population quiet. Second, when the asylum in the 1920s and 1930s shifted to a more curative regime reinforced by the 1930 Mental Treatment Act, this often involved imposition of experimental and hazardous treatments such as brain surgery and electroconvulsive therapy (ECT). The landmark US Schloendorff $\vee$ Society of New York Hospital judgement in 1914 required doctors to obtain patient consent for surgical intervention. While for Judge Cardoza the right to bodily integrity was a cornerstone of a 'free' society, a principle later enshrined in the United Nations Universal Declaration of Human Rights (UHDR), he only applied it to people of 'sound' mind.

\section{The second wave and liberal professionalism in mental health policy (1940s-'80s)}

The second wave of human rights after World War II occurred in the shadow of the Nazi holocaust and state persecution of minorities (Klug, 2000: 9). This had involved 
sterilisation and then the mass killing of mentally and physically disabled people in 1939 as a prelude to the genocide of Jewish people, gay men, gypsies and political undesirables (Lifton, 1986). According to Klug (2000: 97), 'a shared moral revulsion' against these outrages helped lead to the United Nations Universal Declaration of Human Rights (UDHR). It also resulted from the advance of labour and socialist movements and anti-colonial struggles. These were reflected in key principles of human dignity, equality, anti-discrimination and community, not just negative liberties but positive 'economic, social and cultural' (ESC) rights. Yet since in capitalist societies the latter were officially viewed as discretionary, the ability to realise them depended on national political mobilisations.

In mental health, while a new deal was promised as part of the post-war settlement, people with mental health problems were seen as having a lower claim to both CP and ESC rights. Civil liberties were seen as more conditional and subject to medical oversight under the 1959 Mental Health Act (1959), within a system that had a 'Cinderella' status within the NHS, and a wider welfare state that failed to develop adequate community facilities. Little protection was given by the 1950 European Convention on Human Rights (ECHR) of the Council of Europe (not to be confused with the European Union). It was ratified in 1951 and in 1966 Wilson's Labour government agreed to let citizens take individual cases to the European Court in Strasbourg. The ECHR went beyond the UDHR in holding governments directly accountable through the Court, but apart from the right to education, it was restricted to $\mathrm{CP}$ rights. It protected the right to life; it prohibited torture, slavery and forced labour; it protected the right to liberty and security, freedom of expression and assembly, and the right to privacy and family life; it prohibited discrimination on grounds of sex, race colour, language, religion, opinion and national social origin (see Table 1). The ECHR defined some rights such as prohibition of slavery, torture and no punishment without law as absolute. Other rights are qualified, and as far as mental health is concerned, Article 5(e), the 'Right to liberty and security' allows for:

The lawful detention of persons for the prevention of the spreading of infectious diseases, of persons of unsound mind, alcoholics or drug addicts or vagrants.

This negative and stigmatising clause continues to hold sway, limiting possibilities for advancing human rights within mental health. Although government interference in rights must be no more than is 'necessary' (proportionality principle), and adopt 'the least restrictive' alternative (Hoffman and Roche, 2006: 106-8), it is fundamentally protective of state psychiatric power.

Despite the inadequacies of the ECHR, the general climate was one in which rights could be pressed and extended conditionally to people with mental health problems. Newly formed international organisations, the World Health Organisation and World Federation of Mental Health also pressed governments to reform psychiatric care. Though the $1959 \mathrm{MHA}$ and development of community care were partly the result of these as well as an internal logic towards a curative medical model, it was additionally facilitated by a broader spread of citizenship rights, which led to its absorption within the NHS, extension of social security rights and a post-war employment boom. Human rights campaigns to demolish the asylum system were also mounted by social movements, notably the National Council for Civil Liberties (NCCL), now Liberty, to release the thousands it 
Table 1 The European Convention for the Protection of Human Rights and Fundamental Freedoms, and 1998 Human Rights Act

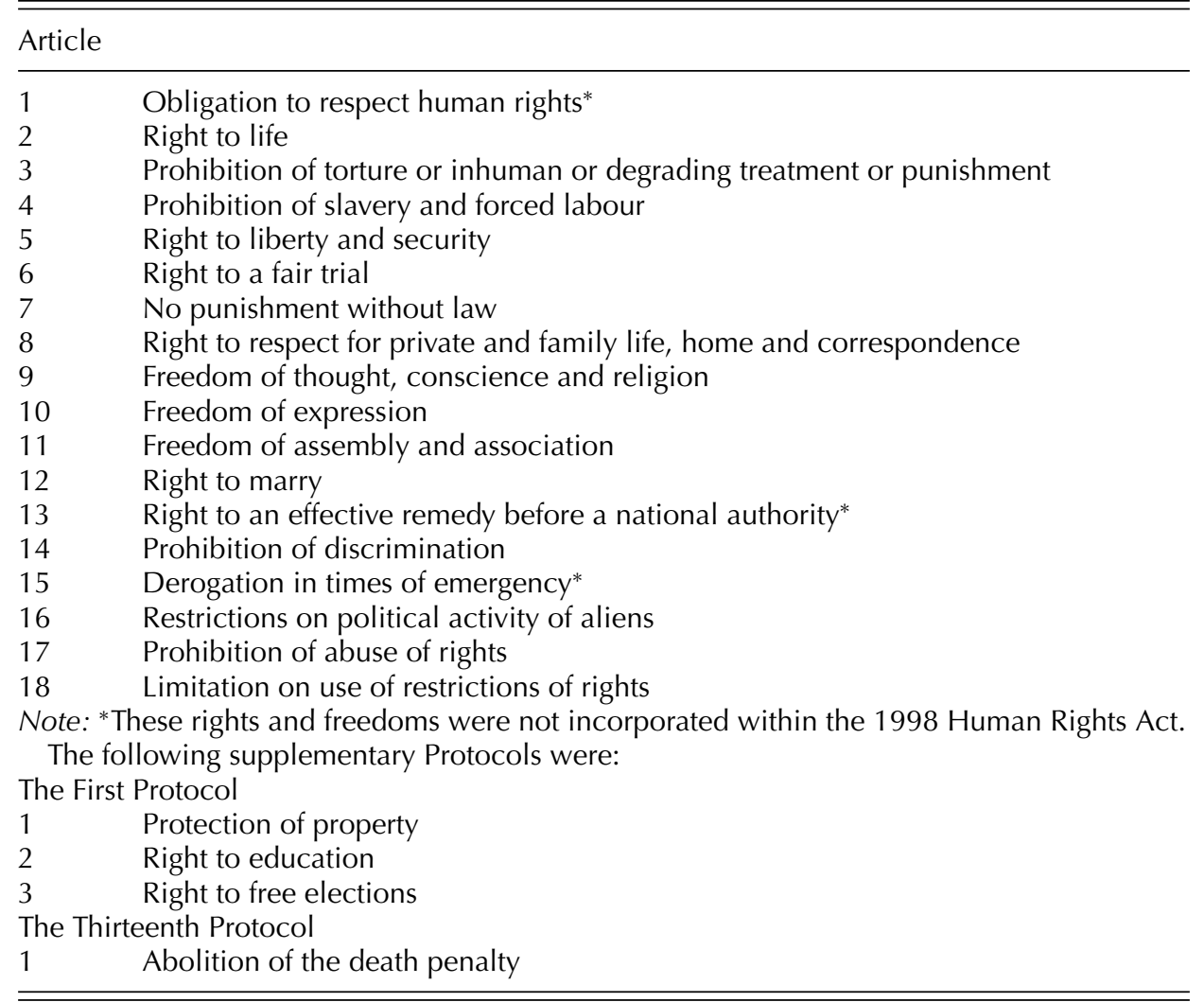

Source: Hoffman and Rowe, 2006: Appendices 1 and 2

claimed had been wrongly incarcerated in mental deficiency institutions, and the Socialist Health Association (SHA) was also influential in the creation of the Mental Health Review Tribunals (MHRTs) (Fennell, 1996). Yet the most distinctive feature of the 1959 MHA was the restoration of medical discretion, on the assumption that most treatments in hospital would be voluntary and a modernised psychiatric profession would protect the best interests of those compulsorily admitted and treated.

Not long after the 1959 MHA, mental health policy became an ideological battleground. Promised community services largely failed to appear, the abuse of patients in hospitals generated a series of scandals, and radical critics like Laing and Szasz claimed that medical discretion simply masked psychiatric oppression. By the early 1970s, a mental health service users' movement had also started to emerge in opposition to state sanctioned medical paternalism (Crossley, 2006). Controversially, the Church of Scientology portrayed the psychiatric profession as an international conspiracy bent on 'mind control', and set up an anti-psychiatry Citizens' Commission on Human Rights in 1969, initially supported by Thomas Szasz. Although the pressure group MIND repulsed infiltration by the Church, it subsequently shifted in a more activist direction. Its' legal 
Table 2 The Winterwerp Criteria of the European Court Judgement 1979

\begin{abstract}
This clarifies under Winterwerp v The Netherlands the circumstances under which deprivation of liberty is permitted under Article 5(1)(e) of the ECHR, 'unsoundness of mind':

(i) that a true mental disorder has been established by objective medical expertise ${ }^{1}$

(ii) that the mental disorder is of a kind or degree warranting compulsory confinement; and

(iii) the validity of continued confinement depends on the persistence of such a disorder
\end{abstract}

Source: Fennel, 1999: 111.

officer, Larry Gostin, argued for a 'new legalism' (an oblique reference to Jones's (1972) critique of the 1890 Lunacy Act), limiting the power of psychiatrists, and the sponsoring a series of test cases to the European Court. The necessitated 1983 Mental Health Act (MHA) produced limited changes within the current pathway, but still largely protective of psychiatric discretion. The landmark judgement of the European Court in 1979 resulting from a complaint by a compulsorily detained Dutch Citizen was Winterwerp $v$ the Netherlands. This confirmed Article 5(e) but laid down certain safeguards which became known as the Winterwerp criteria (see Table 2 above), which are still the foundation of European human rights in mental health and the 1998 HRA. They basically endorse the biomedical model and are protective of medical expertise and paternalism. Challenges must therefore focus on denial of due process rather than substantive treatment, as in $X$ $v$ the United Kingdom (1981), brought with the support of MIND, of a patient who had been conditionally discharged from a mental hospital but whose recall was ordered by the Home Secretary under the 1959 MHA. While the substantive reasons were seen as meeting the Winterwerp criteria, the European Court found that the procedures under which his longer-term confinement was maintained did not. Thus, the 1983 MHA gave patients the right to bring tribunal cases more often, and tribunals the right to decide rather than to advise the Home Secretary on release (Fennell, 1996: 106). A Mental Health Act Commission (MHAC) was also established to safeguard the rights of detained patients.

Winterwerp influenced the core 'treatability test' of the 1983 MHA. which laid down that someone with 'psychopathic' disorder could only be compulsorily admitted to 'alleviate or prevent a deterioration' in their condition. Some treatments, notably ECT, required sanctioning by a Second Opinion Appointed Doctor (SOAD), and though psychosurgery without valid consent was proscribed, seclusion (i.e. solitary confinement) was allowed. In requiring full consent for some treatments and not others, it was ethically contradictory. The Act tidied up rather than fundamentally reformed the discretionary system, adding more procedural CP rights. Research by Crimslink and Phelan (1996) showed numbers using MHRTs rose by 135 per cent by 1993 and legal representation was becoming the norm, but significant delays occurred. In 85 per cent of cases decisions of the Responsible Medical Officer (usually psychiatrist) were upheld.

As in the 1959 Act, in the 1983 MHA CP rights and restrictions are defined by one law, while social provision was dealt with separately. Contrary to the hopes of Gostin and MIND, the Act dealt with admission to hospital rather than services, apart from a right to aftercare in Section 117. More important in opening up a new policy pathway was the Conservative government's rapid closure of the discredited mental 
hospitals from 1986, which also required psychiatrists to work closely with other mental health workers in a community-based service. In 1986, Survivors Speak Out was also formed by mental health service users with an explicit human rights brief challenging 'psychiatric oppression', anticipating 'third wave' participation rights which were also facilitated by the Conservative government's shift to consumerism leading up to the 1990 NHS and Community Care Act. Almost immediately afterwards, media 'carnage in the community' stories of Christopher Clunis (diagnosed with schizophrenia) and Michael Stone (diagnosed with personality disorder) shifted governments down more riskoriented and coercive pathways (Butler and Drakeford, 2005). The subsequent reassertion of disciplinary professional power within a medical pathology model has curtailed development of a 'post-psychiatric' service based more on social rights and empowerment strategies (Bracken and Thomas, 2001). In the process, mental health policy became subject to the conflicting pressures which have become heightened during the New Labour era, leading as we shall now see to a messy compromise between risk-oriented and rights-based roads.

The third wave of human rights and third way in mental health policy (1990s onwards)

According to Klug, the third wave of human rights is a 'new trend' building on rather than breaking with the previous two waves. It is characterised by a renewed emphasis on 'fundamental rights', and also on participation in a world in which civil society organisations play an increasingly significant role and there is a reaction against top-down state paternalism (Klug, 2000: 12). The wider context was the collapse of state communism and the apparent triumph of global capitalism. While the new era did involve a neoliberal threat to collectivist notions of social (ESC) rights, Klug suggests that the end of the Cold War also made it possible to transcend the previous artificial polarisation between two kinds of rights. Certainly, the UN's Vienna Declaration and Programme of Action in 1993 asserted their indivisibility. In the face of powerful neoliberal forces such as corporations and transnational institutions like the International Monetary Fund (IMF) and World Trade Organisation (WTO), the third wave has seen increasing efforts to mobilise around international human rights instruments. As Nancy Fraser $(1989,1995)$ points out, these have sought to promote distributive justice, but also foster claims to identity recognition by 'new' social movements and demands to democratise the determination of 'needs'. The way this has shaped the user movements in mental health is addressed by Cresswell and Lewis in this collection.

Klug then examines the extent to which New Labour since 1997 has embraced the third wave, and equivocates somewhat. On the one hand, there are moves in this direction, most notably the 1998 Human Rights Act (HRA), stronger anti-discrimination legislation and the creation of the Equality and Human Rights Commission (ECHR) in 2007, alongside a commitment to democratise services and foster user participation. On the other hand, Third Way communitarian philosophy leads to efforts to 're-balance' rights with responsibilities, such as greater conditionality in social security benefits, increasing compulsion to enter paid work and a more disciplinary approach to deviance and law and order. These contradictory pressures produce government mental health policies which veer between responsive participative and rights-based approaches, and dictatorial communitarian paths, with the latter given the strongest public endorsement. A central 
aim has been what Garland's (1996) analysis of penal policy calls a 'responsibilisation' strategy. In this context, it means efforts, culminating in the $2007 \mathrm{MHA}$, to combine 'tough' risk surveillance and coercion with a 'soft' partnership approach with professionals and user organisations to foster internalised compliance by more 'responsible' users with prescribed drug and treatment regimes. There are thus at least two general sets of 'generative mechanisms' at work, the contradictions of which are experienced in a particularly intense form in the mental health system.

Therefore, the passing of the 1998 HRA and strengthened anti-discrimination legislation was only one side of the coin and while the HRA was a bold political step, it remains essentially a second wave charter, with problematic mental health provisions. The key issue, then, is whether it is possible to build on it, by strengthening the civil and social rights of mental health service users, in the context of a general extension of charter rights and a move away from communitarian strictures in social policy. These broader developments dovetail with the development of what New Labour itself predictably called a Third Way in Mental Health. This in fact built on policy shifts already initiated by Virginia Bottomley in the wake of the 1994 Clunis Inquiry Report under the previous Conservative government, which included Supervised Discharge, and token additional resources of $£ 10$ million. New Labour then elaborated this pathway through Modernising Mental Health Services (DoH, 1998) which proposed 'safe, sound, and supportive' services, announcing clearly that the first priority was public safety. This strategy has aimed primarily at reassuring the public and appeasing the media, rather than being 'evidence-based policy', as the community care era since the 1950s has been associated with declining homicides by those defined as mentally ill (Large et al., 2008: 132). To be fair, New Labour, though publicly claiming that community care had failed, also sought to develop a strategic approach to mental health policy spanning medical and social models. Thus the National Service Framework (NSF) for Mental Health $(\mathrm{DoH}, 1999)$, emphasised mental health promotion and prevention of suicide, access to effective services, priority services for those considered seriously mentally ill and supportive services for carers. Government spokespeople also drew attention to the way that mental health services shared in the substantially increased funding of the NHS (e.g. Appleby, 2007: 1), but this did not fundamentally alter its Cinderella status and associated vulnerability to cuts in localities that were experiencing spending difficulties from 2006 onwards.

Within the overarching communitarian mental health policy, efforts have been made to enhance the position of users generally, and particular groups selectively, depending on degree of political pressure exerted. Race has always been an issue in response to challenges by black communities who have long experienced greater vulnerability to compulsory admission, coercive treatment and lack of choice. This came to a head as a result of the death of David Bennett, a mental health service user who died after being restrained by nurses in a secure psychiatric unit in 1998, the subsequent inquiry attributing this to 'institutional' racism. In the wider context in which the murder of Stephen Lawrence had led to the Race Relations (Amendment) Act, some visible action was required and the result was Delivering Race Equality (DoH, 2005), which promised more appropriate and responsive services, effective monitoring and an emphasis on community engagement and mental health promotion. It is too early to say what difference this will make. Other equality areas have received less attention. There is a Women's Mental Health Care Strategy (DoH, 2003), but the implementation of this has been slow and there is no 
parallel men's mental health strategy. There is no specific strategy in relation to other equality dimensions, such as sexuality, religion and disability, though some prominence is given to mental health of older people in the 2001 National Service Framework for Older People.

Considerable scope for advancing the rights of all groups exist through the shift to positive duties, which moves away from requiring individuals to press grievances, to an agency duty to promote equality, which will be extended to all recognised discriminations if the 2008 Equality Bill becomes law, strengthening the NHS's own Single Equality System. The indications are that paper policies are still a long way from becoming realities. While NHS standards exist to challenge discrimination and ensure equal access to all groups (e.g. DoH, 2004), they are low down the targets hierarchy compared to waiting lists and times and requirements to monitor and tackle risk. There is no class equality strategy. Though tackling health inequalities is now official government policy, mental health hardly figures, with only limited recognition that serious mental health problems lead to higher risks of physical ill health, such as heart disease, cancer and strokes (Osborn et al., 2006). This points to interactions between social inequalities and the compounding effects of discrimination arising from a stigmatised mental health service user identity issues discussed by Warner in this collection in the context of smoking policies and law. Stigma and discrimination against mental health service users was documented by the Social Exclusion Unit (2004) Report and has led to a national campaign, SHIFT, aimed at addressing it (www.shift.org.uk). Alongside this, opportunities exist under New Labour for advancing the rights of mental health service users through the individual choice and involvement agenda. This involves promoting 'personalised' care, 'fitting services round people not people round services', particularly in community-based services, which must involve both 'choice and control' (DoH, 2006: 4-6). As Bogg (2008) points out, this potentially conflicts with the parallel emphasis on 'risk aversion and best interest decisionmaking' and also dovetails with managerial cost containment strategies.

\section{Human rights and mental health: an impact review}

Having considered the contextual issues shaping the government's mental health policy, to what extent has the $1998 \mathrm{HRA}$ acted as a driver for change? We will first consider the legal effects, and then move to consider possible 'cultural' impacts. It is important to note that the HRA involves no substantive change, simply shortening the legal road and making it easier to press cases in British courts. The basis is still the Winterwerp criteria, which prior to 1998 were mainly interpreted restrictively. Thus cases such as Herczegfalvy v Austria (1992) found handcuffing patients 'therapeutically necessary' and seclusion was sanctioned for 'disciplinary' purposes (Hale, 2007: 23). Continuing medical paternalism and 'best-interest' considerations thus ensure that 'European human rights legislation fails to capture much of the coercion experienced by patients in practice' (Richardson, 2008: 230).

The anxieties expressed when the $1998 \mathrm{HRA}$ was being passed that there would be a flood of cases has not materialised. Most challenges focus on Articles 3, 5 and 8. In some cases they showed that the $1983 \mathrm{MHA}$ was not compliant, and this helped to strengthen the government's case for changing mental health law for corrective action through the 2007 MHA. For example, in 2000 the government was found to be in breach of the Convention for imposing a 'nearest relative' on a patient in dispute with their parent. 
Many cases have concerned treatment in the secure hospital sector, which limits wider applications. An important case was R (Wilkinson) v RMO Broadmoor Hospital (2002) involving forcible treatment where the Appeal Court decided it had the right to hear evidence on issues relating to treatment in relation to Articles 3 and 8. Some suggest this may indicate the beginnings of a shift from procedural to substantive issues (Richardson, 2005). There is no breach of 5(1) when calling 'restricted' patients on conditional discharge back to hospital, which means that Supervised Community Treatment (SCT) might prove human rights compliant under the 2007 MHA discussed below, though it will probably be tested. The restrictive approach was reflected early on in two cases brought under Article 8 on rights to privacy and family life, in which it was not found illegal to restrict the visiting of children or monitoring of private phone calls.

If there is little evidence that legal challenges under the HRA are significantly advancing the rights of users, there is also only limited evidence of service improvements occurring through a spreading 'culture of human rights'. The Audit Commission (2003) found that after an initial flurry, public sector interest was waning in the HRA. Instead they were tending to respond to new legislation such as freedom of information and race equalities and giving it greater priority. The HRA was thus seen as just another piece of legislation rather than an overarching framework for developing improved services within which equalities legislation could be incorporated. The British Institute for Human Rights (www.bihr.org.uk) has been particularly proactive, working with public service agencies to develop an embedded human rights 'culture' through pilot projects including mental health. This informed the 'Framework' guidance document produced by the Department of Health (DoH, 2007).

\section{The 2007 MHA and human rights}

In the face of concerted opposition, it was not until 2007 that the government delivered a MHA for England and Wales. The Joint Committee on Human Rights (2007) in its legislative scrutiny of the 2004 Mental Health Bill identified a wide range of human rights concerns and the government did give some ground. The Act broadens the definition of mental disorder from the four previously defined categories to 'any disorder of mind or brain', replacing the 'treatability test' with a looser requirement that intervention will 'alleviate or prevent deterioration' through 'appropriate' treatment. It also removes the previous exclusion that sexual deviancy alone cannot be considered a disorder justifying detention and treatment. Thus the Act potentially widens the net of social control of the psychiatric system. The influence of the Clunis case is seen in provisions for Supervised Community Treatment (SCT), nicknamed 'psychiatric ASBOs'. SCT is a 'long leash' provision ostensibly targeted on 'revolving door' patients, seeking to stabilise them and ensure drug compliance to reduce need for hospital admission and protect public safety. International evidence suggests it may not be effective in preventing remission, and may be more widely applied than intended (Dawson, 2007). There are fears that black and ethnic minority users will be more likely to be subjected to SCT, lowering trust and deterring help-seeking.

The impact of adverse human rights judgements are seen in changes to the 'nearest relative' provision, with civil partnerships recognised, though the 2007 Act stops short of giving users free choice. Concerted pressure led to a duty to provide advocacy services for the majority of detained patients and those subject to SCT. The Act also introduces more 
safeguards for the treatment of children and young people in mental health facilities, with the aim of ensuring that by 2009 no person under 16 years will be treated in an adult ward. Another response to intense criticism was to promise consultation on the Code of Practice for England and Wales, though critics argued they would have stronger force if they were included in the Act (Mental Health Alliance, 2007: 5). In Scotland, where compulsory community treatment was introduced earlier in 2003, the principles were written into legislation, along with strong advocacy provisions.

The Mental Capacity Act (MCA) 2005 created real difficulties for the government as it emphasises that treatment should be voluntary where people have capacity. It enshrines principles such as self-determination and informed consent, and enables people to state future treatment wishes in advance of losing competency. The Mental Health Foundation had wanted this to be incorporated in the Act, but instead it is simply referred to in the Code of Practice. While competent patients may refuse treatment for physical ill health, treatment for mental ill-health may be legally imposed, subject to second opinion procedures. There is a strong case to be made that separate mental health legislation is inherently discriminatory, and some propose a merger with incapacity legislation to ensure consistent ethical principles across medical law (Dawson and Szmukler, 2006). A systematic review of research into mental capacity found that a majority of psychiatric in-patients have capacity (Okai et al., 2007).

Finally, debates around mental health and human rights have primarily focused on those compulsorily detained. This arguably diverts attention away from two other groups. First, those who may be informally treated, but as we have seen are subject to discrimination and even abuse in the mental health services and wider society (Thornicroft, 2006). Second, the expansion of prisons in a law and order society has arguably led to 'reinstitutionalisation', with ONS statistics suggesting that 90 per cent of prisoners have at least one mental disorder (APPGPH, 2006).

\section{Conclusion: towards a third wave mental health policy}

This article has shown that advances in mental health policy have occurred at key moments of broader change, though their force has been blunted by the combined effects of communitarian imperatives towards social control on the grounds of 'public interest', and medical paternalist treatment impositions justified in the name of users' 'best interests'. This psychiatric 'double helix' has reproduced itself through changing mental health policies throughout and beyond the asylum and mental hospital eras. The current provisions in the 2007 MHA for long leash provisions aimed at people diagnosed with schizophrenia and preventative detention for people diagnosed with personality disorders undoubtedly illustrate this. Yet, while helpfully highlighting the obstacles to change, there is a danger that path dependency analysis can encourage undue pessimism. In this conclusion I therefore argue that while the HRA and anti-discrimination legislation has not yet had profound effects on mental health policy, the genie is out of the bottle and there are possibilities to press rights and challenge communitarian priorities in two ways.

First we have seen that there is considerable scope within existing human rights and equalities legislation, which will be strengthened by the likely emergence of a single 'positive duty' on public agencies, overseen by the Equality and Human Rights Commission (EHRC). While mental health discrimination intersects with others, the 
most promising linkage is perhaps with the disability movement. Immediately prior to its merger into the EHRC, the Disability Rights Commission (DRC) (2007) produced a policy document calling on it to use the Disability Duty to help end discrimination and exclusion of people with mental health problems, including high rates of unemployment, poor life expectancy and bans on jury service, becoming a company director, magistrate or MP. It linked these to the broader need to tackle poverty on human rights grounds and urged the ECHR to take a 'principled' human rights stand on mental health law. As far as mental health law is concerned, the Code of Practice under the 2007 MHA endorses 'value-based practice' and 'recovery' models of care. While these provide some potential for shifting away from a narrow adherence to the biomedical and paternalistic medical models, they are also contestable. As Spandler and Calton argue in their contribution to this collection, human rights provisions currently negate 'madness' as part of human experience. A third wave approach potentially opens up the possibility of challenging such negation. What would also be required above all would be to move human rights and equality higher up the policy and targeting agenda, seeing user empowerment and choice as equality issues, the basis for which does exist within the joint DH/BIHR (2007) guidance. HRA challenges around the 2007 Act may also help, though past experience does not suggest that too much hope should be placed in them.

The second alternative is an extension of human rights frameworks in accordance with third wave principles. This could be facilitated by the establishment of a human rights 'duty' alongside those that will exist in recognised areas of discrimination when the 2008 Equality Bill is passed (McCrudden, 2005: 11). Another prerequisite is a concerted move away from a biomedical model of individual pathology and patient compliance towards one linked to the social model of disability, as argued by Lewis and Spandler and Calton in this and Lewis below, this issue. At the international level, one promising development is the 2006 UN Convention on the Rights of Persons with Disabilities, which represents a 'paradigm shift' away from medical paternalism towards a rights-based social model (www.un.org/disabilities/default.asp?navid=12\&pid=150). Although the UK was one of the first signatories, it is not clear at the time of writing whether it will ratify it in full, including the Optional Protocol, without reservations before the end of 2008. Another key development, informed by a 'third wave' human rights approach, is the Council of Europe 2000 White Paper and 2004 recommendation on the 'fundamental freedoms of persons with mental disorders'. It was accepted by all member states with the exception of the United Kingdom, which 'reserved the right to comply or not', citing as reasons the then Bill and now 2007 MHA (Jones, 2005). There are four broad principles: equality, less restriction, objectivity and separation of involuntary placement and therapy. The most far-reaching feature of the new policy is Article 3 which calls for the prohibition of all forms of discrimination on the grounds of mental disorder alone. In addition, the new proposed protocol extends civil liberties at the same time as establishing ESC rights to 'a range of services of appropriate quality', equal care for physical illness and equivalent care for those inside or out of prison. It states that involuntary detention should not automatically sanction involuntary treatment. Living conditions should as closely as possible match those of the wider society, taking account of age, gender and culture.

Lastly, with the international economic crisis of 2008, in the context of a new US president taking office in January 2009, it is clear that the world has reached 
a new 'critical conjuncture' with possible implications for human rights and mental health. In the UK negative consequences include the rise in poverty, unemployment, debt and repossessions, which will impact negatively on mental health, and mental health users are likely to experience even greater exclusion from the labour market. However, the failure of neoliberalism and unbridled individualism may lead to a revival of collectivism and state intervention, conducive to a consolidation of $\mathrm{CP}$ and extension of ESC rights. In this context the call to include both within a Bill of Rights and Freedoms by the Joint Committee on Human Rights (2008), ensuring that the most vulnerable in society are protected, lays down an important benchmark around which mental health campaigners can rally, especially if implemented alongside the Council of Europe proposed Protocol on mental health. Perhaps we can now 'dare to hope' that such things are possible, envisaging a future based on mentally healthy public policy, involving an inclusive vision of what it means to be human, and a broad conception of associated rights.

\section{Note}

1 That is, not simply deviating from a society's social norms. Detention for protection of others, not just in response to an immediate danger is within the 'margin of discretion' permitted by the Council of Europe

\section{References}

All-Party Parliamentary Group on Prison Health (APPGPH) (2006), The Mental Health Problem in UK HM Prisons, London: House of Commons.

Appleby, L. (2007), Mental Health Ten Years On: Progress on Mental Health Reform, London: Department of Health.

Audit Commission (2003), Human Rights: Improving Public Service Delivery, London: The Audit Commission.

Bhaskar, R. (1975), A Realist Theory of Science, London: Verso.

Bogg, D. (2008), 'Personalisation in mental health care: some initial thoughts', Social Perspectives Network, http://www.spn.org.uk/fileadmin/SPN_uploads/Documents/db_personalisation.pdf

Bracken, P. and Thomas P., (2001), 'Postpsychiatry a new direction for mental health', British Medical Journal, 322, 724-7.

Butler, I. and Drakeford, M. (2005), Scandal, Social Policy and Social Welfare, second edition, Bristol: Policy Press.

Crimlisk, H. and Phelan, M. (1996), 'Mental Health Review Tribunals: time for a change?', British Journal of Psychiatry, 169, 6, 678-81.

Crossley, N. (2006), Contesting Psychiatry: Social Movements in Mental Health, London and New York: Routledge.

Dawson, J. and Szmukler, G. (2006), 'Fusion of mental health and incapacity legislation', British Journal of Psychiatry, 188, 504-9.

Dawson, K. (2007), Briefing 2: Supervised Community Treatment, London: MIND, http://www.mind. org.uk/Information/Legal/MHAlegalbriefing2.htm.

Department of Health (DH) (1998), Modernising Mental Health Services: Safe, Sound and Supportive, London: Department of Health.

DoH (1999), National Service Framework for Mental Health, London: Department of Health. 
DoH (2003), Mainstreaming Gender and Women's Mental Health: Implementation Guidance, London: Department of Health.

DoH (2004), National Standards, Local Action: Health and Social Care Standards and Planning Framework 2005/06-2007/08, London: Department of Health.

DoH (2005), Delivering Race Equality in Mental Health Care: An Action Plan For Reform Inside and Outside Services and The Government's Response to the Independent Inquiry into The Death Of David Bennett, London: Department of Health.

DoH (2006), Our Health, Our Care, Our Say: A New Direction for Community Services, London: The Stationery Office.

DoH (2008), Code of Practice Mental Health Act 1983: Published Pursuant to Section 118 of the Act, London: The Stationery Office.

DoH/BIHR (2007), Human Rights in Healthcare - A Framework for Local Action, London: Department of Health/British Institute of Human Rights.

Disability Rights Commission (DRC) (2007), Coming Together: Mental Health, Equality and Human Rights, London: Disability Rights Commission.

Fennell, P. (1996), Treatment without Consent: Law, Psychiatry and the Treatment of Mentally Disordered People since 1845, London and New York: Routledge.

Foucault, M. (1977), Discipline and Punish: The Birth of the Prison, London: Allen Lane.

Fraser, N. (1989), 'Talking about needs: interpretative contests as political conflicts in welfare state societies', Ethics, 99, 2, 291-313.

Fraser, N. (1995), 'From redistribution to recognition? Dilemmas of justice in a "post-socialist" Age', New Left Review, 212, 68-93.

Garland, D. (1996), 'The limits of the sovereign state: strategies of crime control in contemporary society', British Journal of Criminology, 36, 4, 445-71.

Hale, B. (2007), 'Justice and equality in mental health law: the European experience', International Journal of Law and Psychiatry, 30, 1, 18-28.

Hervey, N. (1986), 'Advocacy or folly: the alleged Lunatics' Friend Society, 1845-63', Medical History, 30, 245-75.

Hoffman, D. and Rocke, J. (2006), Human Rights in the UK: An Introduction to the Human Rights Act 1998, second edition, Harlow, Essex: Pearson Education.

Hunt, L. (2007), Inventing Human Rights: A History, New York: W. W. Norton.

Ishay, M. (2004), The History of Human Rights: From Ancient Times to the Globalization Era, Berkeley: University of California Press.

Joint Committee on Human Rights (2007), Legislative Scrutiny: Mental Health Bill, Fourth Report of Session 2006-7, London: The Stationery Office.

Joint Committee on Human Rights (2008), A Bill of Rights for the UK, Twenty Ninth Report of Session 2007-8, London: The Stationery Office.

Jones, K. (1972), A History of the Mental Health Services, London: Routledge \& Kegan Paul.

Jones, R. (2005), 'Council of Europe recommendation on human rights and psychiatry: a major opportunity for mental health services', European Psychiatry, 20, 461-64.

Klug, F. (2000), Values for a Godless Age: The Story of the UK's New Bill of Rights, Harmondsworth: Penguin.

Large, M., Smith, G., Swinson, N., Shaw, J. and Nielssen, O. (2008), 'Homicide due to mental disorder in England and Wales over 50 years', British Journal of Psychiatry, 193, 2, 130-3.

Lifton, R. J. (1986), The Nazi Doctors: Medical Killing and the Psychology of Genocide, New York: Basic Books.

McCrudden, C. (2005), 'Mainstreaming human rights', in C. Harvey (ed.), Human Rights in the Community: Rights as Agents of Change, Oxford: Hart Publishing, pp. 9-28.

Mental Health Alliance (2007), The MHA 2007: The Final Report, London: Mental Health Alliance.

Mental Health Foundation (2007), The Fundamental Facts: The Latest Facts and Figures on Mental Health, London: Mental Health Foundation. 
Murali, V. and Oyebode, F. (2004), 'Poverty, social inequality and mental health advances in psychiatric treatment', 10, 216-24.

Okai, D., Owen, G., McGuire, H., Singh, S., Churchill, R. and Hotopf, M. (2007), 'Mental capacity in psychiatric patients: systematic review', British Journal of Psychiatry, 191, 291-7.

Osborn, D., Nazareth, I. and King, M. (2006), 'Risk for coronary heart disease in people with severe mental illness: cross-sectional comparative study in primary care', British Journal of Psychiatry, 188, $271-7$.

Pierson, P. (2001), The New Politics of the Welfare State, Oxford: Oxford University Press.

Richardson, G. (2005), 'The European convention and mental health law in England and Wales: moving beyond process?', International Journal of Law and Psychiatry, 28, 127-39.

Richardson, G. (2008), 'Coercion and human rights: a European perspective', Journal of Mental Health, $17,245-54$.

Scull, A. (1993), The Most Solitary of Afflictions: Madness and Society in Britain 1700-1900, New Haven: Yale University Press.

Social Exclusion Unit (2004), Mental Health and Social Exclusion, London: Office of the Deputy Prime Minister.

Thornicroft, G. (2006), Shunned: Discrimination against People with Mental Illness, Oxford: Oxford University Press.

Weiner, D. B. (1994), '"Le gest de Pinel": the history of a psychiatric myth', in M. S. Micale and R. Porter (eds), Discovering the History of Psychiatry, Oxford: Oxford University Press.

Wilsford, D. (1995), 'Path-dependency, or why history makes it difficult, but not impossible to reform health care services in a big way', Journal of Public Policy, 14, 251-83. 